\title{
Nilai Tolong-menolong dalam Tradisi Pengajian Parkahanggian Marga di Desa Pidoli Lombang Kabupaten Mandailing Natal (Kajian Living al- Qur'an)
}

\author{
Azhar Nasution ${ }^{1}$, Rusydi $\mathrm{AM}^{2}$, Widia Fithri ${ }^{3}$ \\ UIN Imam Bonjol Padang \\ azharnasution1996@gmail.com
}

\begin{abstract}
Pengajain Parkahanggian in which it has a strong mutual help value. The Parkahanggian Marga recitation is a religious activity that reads the verses of the Qur'an in it and brings the verses of the Qur'an to life by reading and practicing it. This research is a qualitative field research, using descriptive analysis method, data collection using observation, interview and documentation techniques. Based on this research, the authors found that the tradition of the Parkahanggian recitation in Pidoli Lombang village has been going on for a long time, some findings indicate that this recitation came from Shaykh Ma'sum who lived in the village, some said that this recitation was started by the parkahanggian clan of Borotan. Some of the motivations for the community to conduct this recitation are to help each other, preserve traditions, do good deeds and send rewards to those who have gone before, and establish friendship. The first phase of the Parkahanggian recitation procession was reading verses from the Qur'an such as al-Fatibah, alIkblas, al-Falaq an-Nas, al-Baqarah, tablil and prayer, the second phase was markobar (speaking), the last phase was marpio (calling). name), this recitation was held on Friday night after the Isa prayer, the men involved. This recitation is a place for mutual belp between brothers and sisters in the same family, in this tradition there are also Qur' anic values that are understood and practiced. Its implementation involves all heads of households. The value of mutual assistance is very thick in this Parkahanggian recitation both in joy and sorrow. Among the forms of mutual assistance are assistance in the form of energy, money and thoughts that are donated and given when there are parties and misfortunes, kahanggi will be very belpful. All of that departs from people's understanding of the teachings of the Qur'an to do good.
\end{abstract}

Keyword: Living al-Qur'an, Pengajian Parkahanggian Marga, Tolong-melolong

Abstrak. Pengajain Parkahanggian di dalamnya mempunyai nilai tolong-menolong yang kental. Pengajian Parkahanggian Marga adalah suatu kegiatan keagamaan yang membaca ayat al-Qur'an di dalamnya dan menghidupkan ayat al-Qur'an dengan dibaca dan diamalkan. Penelitian ini bercorak penelitian lapangan (field research) yang memotret fenomena penghidupan di masyarakat yang bersifat kualitatif, dengan menggunakan metode analisis deskriptif, pengumpulan data menggunakan teknik observasi, wawancara dan dokumentasi. Berdasarkan penelitian ini penulis menemukan bahwa tradisi Pengajian Parkahanggian di desa Pidoli Lombang telah berlangsung lama, beberapa temuan menunjukkan bahwa pengajian ini berasal dari syaikh Ma'sum yang menetap di kampung tersebut, ada juga yang mengatakan 
Az̧bar Nasution, Rusydi AM, Widia Fithri, Nilai Tolong-menolong dalam Tradisi Pengajian Parkahanggian Marga di Desa Pidoli Lombang Kabupaten Mandailing Natal (Kajian Living al-Qur'an)

pengajian ini dimulai oleh parkahanggian marga Borotan. Beberapa motivasi masyarakat melakukan pengajian ini untuk saling menolong, melestarikan tradisi, amal ibadah dan kiriman pahala kepada yang telah terdahulu, serta menjalin silaturahim. Prosesi pengajian Parkahanggian fase pertama membaca ayat-ayat alQur'an seperti al-Fatihah, al-Ikhlas, al-Falaq an-Nas, al-Baqarah, tahlil dan doa, fase kedua markobar (berbicara), fase terakhir marpio (pemanggilan nama), pengajian ini dilaksanakan malam Jum'at selepas salat Isa yang terlibat didalamnya adalah kaum laki-laki. Pengajian ini merupakan wadah untuk saling tolong-menolong antar yang bersaudara semarga, dalam tradisi ini juga terdapat nilai-nilai al-Qur'an yang dipahami dan diamalkan. Pelaksanaannya melibatkan semua kepala rumah tangga. Nilai tolong-menolong sangat kental dalam pengajian Parkahanggian ini baik dalam suasana suka maupun duka diantara bentuk saling membantu tersebut adalah bantuan berupa tenaga, uang dan pikiran yang disumbangkan dan diberikan ketika ada acara pesta dan kemalangan kahanggi akan sangat membantu. Semua itu berangkat dari pemahaman masyarakat terhadap ajaran al-Qur'an berbuat kepada kebaikan.

Kata Kunci: Living al-Qur'an, Pengajian Parkahanggian Marga, Tolongmelolong

\section{PENDAHULUAN}

Al-Qur'an menjadi suatu perkara yang penting ketika manusia menjadikan al-Qur'an sebagai amalan rutin bagi mereka yang membudaya dan menjadi tradisi yang menempatkan al-Qur'an di urutan pertama dan terpenting dalam mempelajari agama Islam.(Makhdlori 2019:16) berbagai urusan ketuhanan dan sosial masyarakat juga tercantum dalam al-Qur'an, Semisal tolong-menolong juga sudah dijelaskan di dalam al-Qur'an yaitu ta'awun, nilai ta'awun sangat dijunjung tinggi oleh Islam yaitu tolong-menolong antar sesama manusia diantaranya kerjasama dalam kebaikan kepada jalan kemaslahatan bersama.(Nashir 2019:11)

Allah menjelaskan di dalam al-Qur'an pada surah al-Maidah ayat 2 yaitu: 


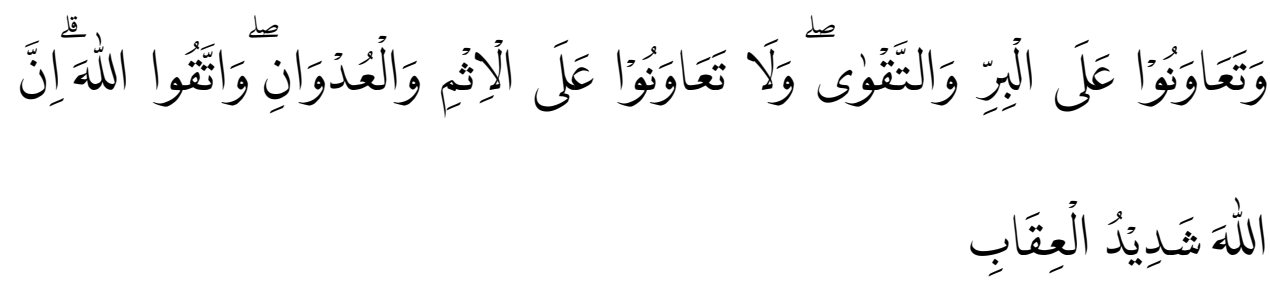

"Dan tolong-menolonglah kamu dalam (mengerjakan) kebajikan dan takwa, dan jangan tolong-menolong dalam berbuat dosa dan pelanggaran dan bertakwalah kamu kepada Allah, sesunggubnya Allah amat berat siksaNya." (Q.S al-Maidah:2)

Allah swt, memberi arahan dari ayat di atas bahwa tolong-menolong kepada kebaikan sangatlah dianjurkan. Selama ini berbagai riset tentang tolong-menolong telah banyak ditemui, namun berbagai riset tersebut tidak menyoroti tentang pengajian parkahanggian yang di dalamnya mengandung nilai tolong-menolong yang kental secara khusus melainkan hanya kepada fokus tertentu, seperti penelitian Delvia Sugesti dalam temuannya menyebutkan bahwa hakikat tolong-menolong tujuannya kebaikan adalah: 1 . Dapat lebih memperkuat tali persaudaraan, 2. Mewujudkan kehidupan harmonis dan tentram, 3. Menimbulkan rasa persatuan antara sesama manusia.(Sugesti 2019:121). Selanjutnya, dalam tradisi Jawa Adi Mandala Putra menyatakan dalam jurnalnya tolong-menolong mempunyai istilah tersendiri yaitu sambatan di daerah Jawa dikenal sebagai sistem tolongmenolong kepada yang tertimpa musibah guna untuk meringankan bebannya, kegiatan sambatan ini biasa dilakukan di daerah pedesaan Jawa.(Putra and Bahtiar 2018:476)

Selanjutnya, seiring dengan berjalannya waktu bagi umat Islam pasti mempunyai keyakinan bahwa al-Qur'an merupakan kitab yang memiliki berbagai fungsi, baik dalam mempelajari, membaca dan memfungsikan alQur'an itu sendiri, di Indonesia misalnya banyak tradisi berupa perilaku di 
Az̧ar Nasution, Rusydi AM, Widia Fithri, Nilai Tolong-menolong dalam Tradisi Pengajian Parkahanggian Marga di Desa Pidoli Lombang Kabupaten Mandailing Natal (Kajian Living al-Qur'an)

masyarakat yang menurut mereka berlandaskan kepada al-Qur'an itu sendiri misalnya pada kasus tolong-menolong di masyarakat lampung ada istilah begawi, penelitian ini menyoroti pada kasus tradisi adat perkawinan dengan beberapa tahap 1. Cakak sai tuha 2. Menyesuai Kician 3. Mohon Persetujuan Perkawinan.(Fitri 2019:iii) Tradisi ini mempunyai nilai tolong-menolong dalam hal upacara perkawinan.

Selain penelitian di atas, pengalaman berinteraksi dengan al-Qur'an adalah suatu hal yang kerap ditemui seperti membaca Yasin 41 yang diperuntukkan bagi orang yang sakit kafiatnya dipercaya untuk menyembuhkan, akan tetapi bukan hanya itu dengan membaca surah Yasin tersebut maknanya telah menghidupkan al-Qur'an.(Simamora 2021:5). Seterusnya pembacaan ayat al-Qur'an dan mengamalkan maknanya juga diharuskan bagi seorang muslim, seperti penelitian Nana Istiana PT. Karya Toha Putra Semarang mempunyai suatu kebiasaan yang sudah menjadi rutinitas sebelum memulai pekerjaan yaitu membaca al-Qur'an yang dilakukan setiap harinya.(Istianah 2020:xi). Selanjutnya, untuk menghidupkan al-Qur'an itu sendiri membaca al-Qur'an bisa juga dimana saja, seperti halnya mengaji di kuburan masyarakat Indonesia kerap kali mengaji di kuburan untuk menghadiahkan pahala kepada kerabat yang telah meninggal, dalam temuannya terdapat tiga model praktek mengaji al-Qur'an di kuburan yang dijumpai dalam masyarakat. Pertama, mengaji al-Qur'an setelah penguburan sampai khatam, Kedua, mengaji al-Qur'an pada hari Jum'at, ketiga, mengaji al-Qur'an setelah shalat ied dengan membaca beberapa surat pilihan.(Nuraini and Jannah 2020:17)

Mengamalkan makna al-Qur'an juga diwajibkan bukan hanya membacanya, seperti riset mengenai organisasi act riau oleh Elizabet Kristi menyatakan dalam temuannya bahwa act riau adalah wadah yang menyebarkan informasi dan menampung bantuan para donatur. Salah satu program yang dilakukan Aksi Cepat Tanggap Riau adalah sumur wakaf yang 
Az̧bar Nasution, Rusydi AM, Widia Fithri, Nilai Tolong-menolong dalam Tradisi Pengajian Parkahanggian Marga di Desa Pidoli Lombang Kabupaten Mandailing Natal (Kajian Living al-Qur'an)

membantu orang-orang muslim yang kekurangan air dan juga mendapat fasilitas tempat wudhu dan toilet.(Kristi 2021:ix)

Potret riset di atas jelas berbeda dengan penelitian yang penulis lakukan, tulisan ini terfokus pada tolong-menolong dalam tradisi pengajian parkahanggian marga di desa Pidoli Lombang dengan pendekatan teori living al-Qur'an. Tolong-menolong ini juga sudah menjadi tradisi dan adat istiadat di suatu daerah atau perkotaan, dari hemat penulis tradisi ini begitu unik dan khusus, praktek ini adalah fenomena living al-Qur'an yang bersumber dari keyakinan masyarakat terhadap al-Qur'an.(Sudarmoko 2016:2).

Setelah ditelusuri praktek seperti ini tidak terdapat di daerah lain dan mereka masih melakukan tradisi tersebut hingga sekarang, yaitu biasa disebut oleh masyarakat tradisi Pengajian Parkahanggian Marga, pengajian ini berada di daerah Mandailing Natal tepatnya di desa Pidoli Lombang Kecamatan Panyabungan. Mandailing ini merupakan masyarakat yang majemuk mempunyai slogan "Negeri Beradat Taat Beribadat".(Asrin 2020:7) Mandailing juga dijuluki sebagai serambi mekkahnya Sumatera Utara,(Effendi 2018:4) selain pesantren juga di Mandailing masih kental dengan aktivitas keagamaan seperti Pengajian Parkahanggian yang ada di desa Pidoli Lombang ini.

Selanjutnya, terdapat sedikit gambaran tentang tradisi pangajian parkahanggian ini, disebut Pangajian Parkahanggian dikarenakan para anggota pengajian tersebut khusus anggotanya dihimpun oleh marga, dari observasi penulis ada beberapa marga yang mengikuti pengajian di Pidoli Lombang ini, diantaranya marga Nasution, marga Borotan, marga Lubis, marga Rangkuti, marga Batubara, Marga Hasibuan, dan pangajian parkahanggian ini mengaji pada malam Jum'at.(Pidoli 2020:Maret-08) H. Aslin Borotan kepala desa Pidoli Lombang yang beliau adalah salah satu tokoh masyarakat di Pidoli Lombang mengatakan bahwa parkahanggian yang 
Az̧bar Nasution, Rusydi AM, Widia Fithri, Nilai Tolong-menolong dalam Tradisi Pengajian Parkahanggian Marga di Desa Pidoli Lombang Kabupaten Mandailing Natal (Kajian Living al-Qur'an)

dimaksud disini adalah suatu istilah yang disematkan ke dalam bahasa Mandailing atau adat istiadat Mandailing yang artinya persaudaraan, dengan pemahaman sederhananya parkahanggian berarti persaudaraan semarga, misalnya parkahanggian marga Nasution maknanya persaudaraan perkumpulan marga Nasution, dalam pengajian ini terkandung di dalamnya nilai tolong-menolong.(H. Aslin Bororan 2021:Januari-17) Adapun yang menjadi keunikan dari tradisi pangajian parkahanggian ini disaat salah satu anggota pengajian mengalami siriaon (Pesta pernikahan) atau siluluton (kemalangan), mereka dari anggota pengajian akan saling tolong-menolong baik itu dalam segi dana, tenaga, pikiran. Baik dalam suasana suka dan duka kelompok masyarakat ini akan saling membantu satu sama lain.

Kasus yang menarik dan perlu untuk diteliti, oleh sebab itu tulisan ini akan mengulas lebih dalam tentang sejarah dan motivasi pengajian parkahanggian, lalu bentuk praktek tradisi pengajian parkahanggian yang dilakukan, dan hikmah yang dirasakan ketika berlangsungnya tradisi pengajian perkahanggian tersebut. Tulisan ini bertujuan mengungkap secara mendalam tradisi pengajian parkahanggian yang mengandung nilai tolong-menolong.

Penelitian ini bersifat kualitatif yaitu secara langsung penulis terjun ke lokasi dan objek yang diteliti, dengan menggunakan metode analisis deskriptif yaitu menggambarkan objek yang diteliti sebagaimana adannya sesuai dengan data yang diperoleh dilapangan.(Azwar 2016:7) Pengumpulan data menggunakan teknik observasi dan wawancara dan dokumentasi. .(Sangadji and Sopiah 2010:199) Teori yang dipakai dalam penelitian ini adalah teori living al-Qur'an garapan studi living al-Qur'an ialah tentang berbagai peristiwa sosial terkait dengan kehadiran al-Qur'an atau keberadaan al-Qur'an pada komunitas muslim. Berinteraksi dengan al-Qur'an termasuk kepada kategori living al-Qur'an, pengalaman berinteraksi ini banyak menghasilkan 
Az̧bar Nasution, Rusydi AM, Widia Fithri, Nilai Tolong-menolong dalam Tradisi Pengajian Parkahanggian Marga di Desa Pidoli Lombang Kabupaten Mandailing Natal (Kajian Living

pemahaman dan penghayatan yang kemudian diaplikasikan dalam kehidupan sehari-hari.(M. Mansyur 2007:5) Penelitian semacam ini lebih fokus kepada peran praktis al-Qur'an, aktivitas individu atau masyarakat umum, serta membahas pemahaman sekelompok masyarakat terhadap ayat al-Qur'an bukan penafsiran al-Qur'an.(Ali 2015:153) Memfungsikan al-Qur'an sama saja dengan bagaimana masyarakat meresepsi al-Qur'an itu sendiri,(Suriani 2018:6)oleh sebab itu mengkaji resepsi al-Qur'an bukan hanya mengkaji teks tertulis, tapi juga mengamati masyarakat dimana al-Qur'an dibaca, ditafsirkan dipraktekkan dan digunakan atau dimanfaatkan dalam berbagai tujuan.(Zuhri and Syamsuddin 2012:77).

\section{HASIL DAN PEMBAHASAN}

\section{Sejarah dan Motivasi Tolong-menolong dalam Tradisi Pengajian Parkahanggian}

Asal-usul tradisi pengaiian parkahanggian di desa Pidoli Lombang ini penulis menemukan beberapa latar belakang kemunculannya, menurut Fahri Lubis tradisi pengajian parkahanggian ini telah lama dilaksanakan di kampung tersebut, ini adalah tradisi pengajian turun-temurun yang telah ada sejak lama beliau mengatakan semenjak lahir pengajian ini sudah terbentuk.(Fahri Lubis 2021:Januari-16) Senada dengan penjelasan di atas Unan seorang tokoh masyarakat juga menyebutkan bahwa pengajian parkahanggian ini tidak diketahui tahun berapa berdiri, dan tidak ditemukan catatan tahun berapa pengjian ini berdiri, tapi menurutnya pengajian ini sudah berlangsung puluhan tahun di desa Pidoli Lombang.(Unan Rangkuti 2021:Januari-15). Penjelasan di atas menyebutkan bahwa ketika ditanyakan tentang tahun berapa asal mula pengajian parkahanggian ini, informan tidak mengetahui pasti tahun awal terjadinya pengajian parkahanggian ini. Namun penulis menganalisa dari informan yang penulis tanyakan yang telah berusia 50 -an 
Az̧bar Nasution, Rusydi AM, Widia Fithri, Nilai Tolong-menolong dalam Tradisi Pengajian Parkahanggian Marga di Desa Pidoli Lombang Kabupaten Mandailing Natal (Kajian Living al-Qur'an)

ketika dia lahir pengaiian ini sudah ada, penulis berasumsi bahwa pengajian ini dimulai antara tahun 1950 atau 1960 an.

Penulis mencoba mencari keterangan kepada informan lain yaitu Abdul Bais, setelah berbincang-bincang beliau mengatakan bahwa ada kemungkinan pengajian parkahanggian di Pidoli Lombang ini dicetuskan oleh orangtua-orangtua dahulu yaitu yang mengerti betul tentang agama tuan syaikh atau murid dari tuan syaikh yang dahulunya terdapat di desa Pidoli Lombang tuan syaikh tersebut bernama syaikh Ma'sum.(Abdul Bais Nasution 2021:Januari-16) Penjelasan di atas menyebutkan bahwa Abdul Bais berasumsi bahwa yang mendirikan pengajian parkahanggian ini dahulunya adalah syaikh Ma'sum, Memang dari hasil observasi penulis ke lokasi penelitian bahwa benar adanya bahwa syaik Ma'sum ini bertempat tinggan di desa Pidoli Lombang ini dahulunya, dan syaikh ini juga merupakan syaikh yang berpengaruh di daerah Mandailing Natal khususnya di desa Pidoli Lombang.

Dari hasil observasi penulis juga menunjukkan bahwa yang melaksanakan pengajian ini adalah kaum laki-laki di desa Pidoli Lombang. Selanjutnya terkait penamaan pengajian parkahanggian ini menurut Abdul Bais seorang Qori sekaligus guru mengaji di desa Pidoli Lombang mengenai penyematan nama pengajian parkahanggian beliau mengatakan bahwa dinamakannya pengajian parkahanggian karena adanya persaudaraan semarga, maksudnya adalah persaudaraan marga Nasution, persaudaraan Marga Lubis dll. Dinamakan pengajian parkahanggian pengajian ini adalah karena semua kahanggi (bersaudara) semarga, maksudnya disini kahanggi (saudara) semarga, misalnya kahanggi (persaudaran) Nasution, kahanggi (persaudaran) Lubis, Borotan, itulah sebabnya dinamakan pengajian parkahanggian, karena adanya persaudaraan semarga .(Abdul Bais Nasution 2021:Januari-16) 
Ažbar Nasution, Rusydi AM, Widia Fithri, Nilai Tolong-menolong dalam Tradisi Pengajian Parkahanggian Marga di Desa Pidoli Lombang Kabupaten Mandailing Natal (Kajian Living al-Qur'an)

Selanjutnya, landasan dalil yang dipakai masyarakat dalam pelaksanaan pengajian parkahanggian Pengajian Parkahanggian ini adalah dasarnya dari al-Qur'an, membaca ayat-ayat al-Qur'an adalah salah satu anjuran dalam agama Islam. Berbuat baik dan anjuran saling menolong ada di dalam al-Qur'an, yang tercantum dalam firman Allah Q.S al-Maidah-2, dan saling tolong menolonglah kalian dalam hal kebaikan dan takwa.(Muda Mustari 2021:Januari-17)

Selain itu, Syamsuddin seorang tokoh agama juga menjelaskan di pengaiian ini selain beribadah masih ada amalan yang lain yaitu bersedekah saling menolong, perbuatan ini semua ada diajarkan di dalam al-Qur'an dan hadis Nabi, dalam al-Qur'an juga disebutkan dan dijelaskan apabila bersedekah maka Allah akan membalasnya dengan berlipat-lipat ganda ayatnya ialah:

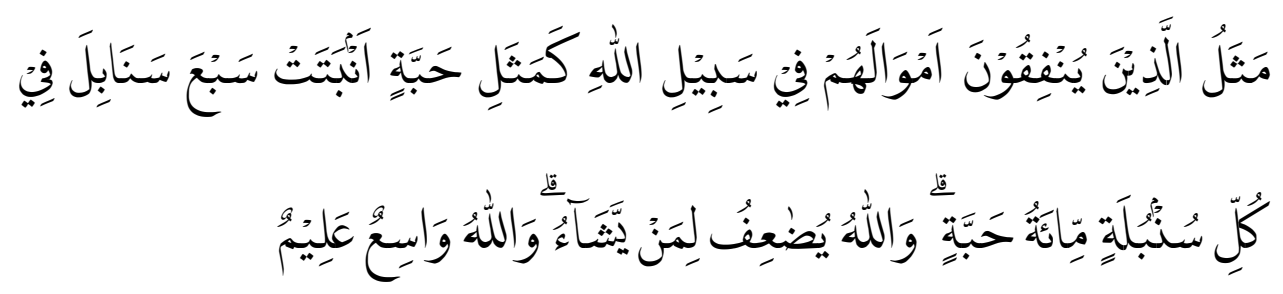

Artinnya: Perumpamaan orang yang menginfakekan hartanya dijalan Allab seperti sebutir biji yang menumbubkan tujub tangkai, pada setiap tangkai ada seratus biji, Allah melipatgandakan bagi siapa yang Dia kehendaki, dan Allah Maha luas, Maha mengetahui (Q.S al-Baqarah: 261)

Begitulah istimewa dan hebatnya bersedekah tersebut, di al-Qur'an pun dijelaskan mengenai bersedekah ini, begitu juga halnya apabila bersedekah kepada masyarakat dengan memberikan bantuan.(Samsuddin 2021:Januari15) 
Az̧ar Nasution, Rusydi AM, Widia Fithri, Nilai Tolong-menolong dalam Tradisi Pengajian Parkahanggian Marga di Desa Pidoli Lombang Kabupaten Mandailing Natal (Kajian Living al-Qur'an)

Selanjutnya, dalam melakukan pengajian parkahanggian ini, ada beberapa motivasi dikalangan masyarakat diantaranya dijelaskan oleh $\mathrm{H}$. Aslen Borotan selaku kepala desa di daerah tersebut menyatakan pengajian ini adalah wadah untuk memotivasi masyarakat untuk saling tolongmenolong, karena perkara tolong-menolong tersebut adalah ajaran yang ada dalam agama Islam, Di desa Pidoli Lombang tersebut perbuatan semacam ini telah menjadi kebiasaan. (H. Aslin Bororan 2021:Januari-17) Temuan lain berasal dari Fahri Lubis salah seorang hatobangon/tokoh adat menyebutkan bahwa kepentingan dari tradisi ini adalah untuk memotivasi masyarakat agar selalu melestarikan pengajian ini karena ini sudah menjadi kebiasaan dan menjadi tradisi di desa Pidoli Lombang, agaknya menurut beliau apabila ada kesempatan markobar (berbicara pada saat acara), beliau selalu menghimbau agar supaya pengajian ini selalu dilestarikan karena ini sudah membudaya dan menghasilkan dampak yang baik bagi masyarakat.(Fahri Lubis 2021:Januari16)

Temuan selanjutnya, penjelasan Abdul Basit beliau mengatakan bahwa salah satu tujuan dan motivasi dari pengajian ini adalah bacaan ayat al-Qur'an tersebut dihadiahkan kepada keluarga yang telah terdahulu meninggal dunia untuk bekal mereka di alam kubur.(Abdul Bais Nasution 2021:Januari-16) Motivasi dalam pengajian ini juga dijelaskan oleh Amrin adalah untuk beribadah, dengan berwirid dan membaca ayat-ayat al-Qur'an menambah ibadah kita kepada Allah. Selain itu, Amrin Borotan mengatakan bahwa pengajian ini adalah untuk mempererat hubungan kekeluargaan dan berkumpul itu adalah suatu rahmat, sebagaimana hadits Nabi الجماعة رحمه و الفرقت عذاب (Jama’ah itu rahmat dan firqah itu adzab).(Amrin Borotan SH 2021: Januari 15) 
Ažbar Nasution, Rusydi AM, Widia Fithri, Nilai Tolong-menolong dalam Tradisi Pengajian Parkahanggian Marga di Desa Pidoli Lombang Kabupaten Mandailing Natal (Kajian Living al-Qur'an)

\section{Prosesi Tolong-menolong dalam Tradisi Pangajian Parkahanggian di desa Pidoli Lombang}

Pada poin ini akan menjelaskan terkait prosesi pengajian parkahanggian serta bentuk tolong-menolong masyarakat Pidoli Lombang yang terbagi kepada tiga poin, yaitu: Pertama, pengajian parkahanggian dan yang terlibat di dalamnya mencakup beberapa marga yaitu marga Lubis, Rangkuti, Nasution, Borotan, Hasibuan, Batubara. Sesuai dengan parkahanggian (saudara semarga) atau marga yang ada di daerah tersebut.(Unan Rangkuti 2021:Januari-15) Hal semakna sama diungkap oleh bayo menjelaskan bahwa ada 6 marga dalam pengajian parkahanggian yang mengaji pada malam Jum'at selepas solat Isya, yaitu marga Borotan, parkahanggian Lubis, parkahanggian Nasution, parkahanggian Rangkuti, parkahanggian Batubara, parkahanggian Hasibuan. (Bayo 2021:Januari-17)

Pada kesempatan ini penulis coba mencari keterangan dari salah seorang tokoh adat di masyarakat Pidoli Lombang yaitu Unan beliau kesehariannya berdagang dan beliau juga aktif di dalam sosial keagamaan di desa Pidoli Lombang, beliau mengatakan prosesi pengajian ini diadakan pada malam Jum'at selepas solat Isya yang dilaksanakan oleh kepala keluarga setiap rumah di Pidoli Lombang, masyarakat Pidoli Lombang setiap Pengajian Parkahanggian akan menyambangi rumah giliran yang ditentukan.(Unan Rangkuti 2021:Januari-15) Setelah penulis mendapatkan informasi bahwa pengajian ini hanya diikuti oleh kaum laki-laki saja yaitu kepala keluarga, penulis mencoba mendalami kenapa mesti laki-laki yang mengikuti pengajian ini. Pada kali ini penulis mewawancarai Fahri Lubis beliau mengatakan bahwa dalam adat Mandailing laki-laki adalah sebagai pemimpin, karena dalam silsilah marga turun dari laki-laki yaitu dari seorang ayah, oleh sebab itulah pengajian parkahanggian ini didominasi oleh kaum laki-laki dari kepala keluarga.(Fahri Lubis 2021:Maret-8) Senada dengan penjelasan dari 
Az̧bar Nasution, Rusydi AM, Widia Fithri, Nilai Tolong-menolong dalam Tradisi Pengajian Parkahanggian Marga di Desa Pidoli Lombang Kabupaten Mandailing Natal (Kajian Living al-Qur'an)

Syamsuddin menyebutkan bahwa mulai dari dahulu sudah disepakati bahwa hanya laki-laki yang ikut pengajian parkahanggian ini, karena dalam adat Mandailing laki-laki adalah pemegang marga, karena dalam budaya Mandailing laki-laki sebagai pemimpin dan dalam acara-acara adat pihak lakilaki yang memegang dan mengatur, kemudian pihak perempuan biasanya memasak. (Samsuddin 2021:Maret-8)

Menurut analisa penulis dari temuan di atas menyebutkan bahwa lakilaki dalam adat Mandailing dianggap seorang pemimpin dan yang lebih berpengaruh dari pada perempuan. Maka dari itu di pengajian parkahanggian ini hanya laki-laki saja yang terlibat di dalamnya, dari penjelasan informan di atas menyebutkan bahwa marga diambil dari pihak laki-laki atau ayah, itulah alasan kenapa hanya laki-laki yang terlibat di dalamnya.

Kedua, prosesi pengajian parkahanghian, dilaksanakan pada malam Jum'at. Dalam hal ini penulis melakukan wawancara dengan Muda Mustari (Tuan Muda) guru mengaji di desa Pidoli Lombang beliau mengatakan bahwa ada beberapa pelaksanaan dan yang dibaca adalah ayat-ayat al-Qur'an, ia mengatakan yang dibaca adalah al-Fatihah dihadiahkan kepada Rasulullah, para Sahabat, keluarga Nabi, dan kepada kaum muslimin dan muslimat, terkhusus kepada ahli bait, keluarga yang telah dahulu, surah al-Ikhlas 9x atau 7x, al-Falaq, an-Nash, al-Fatihah, al-Baqarah ayat 1-5, al-Baqarah ayat 255 (ayat Kursi), al-Baqarah ayat 285-286, al-Ahzab ayat 65, tahlil, salah seorang akan membacakan ayat al-Qur'an, kemudian ditutup dengan do'a, seterusnya markobar, marpio.(Muda Mustari 2021:Maret-17)

Jawaban yang sama dilontarkan oleh Samsuddin mengatakan Setelah masuk kerumah pengajian tersebut, akan ada yang memimpin pengajian itu dengan membacakan surah al-Fatihah, al-Ikhlas, an-Nas, al-Baqarah dan seterusnya sampai pada bacaan tahlil, setelah semua selesai dibaca akan ada 
Az̧bar Nasution, Rusydi AM, Widia Fithri, Nilai Tolong-menolong dalam Tradisi Pengajian Parkahanggian Marga di Desa Pidoli Lombang Kabupaten Mandailing Natal (Kajian Living al-Qur'an)

yang membacakan ayat al-Qur'an terakhir dan ditutup dengan doa, setelah pembacan itu selesai seterusnya adalah markobar, dan marpio berpanggil nama, dipanggil satu persatu nama anggota guna untuk memberikan iuran bantuan.(Samsuddin 2021:Maret-15) Ketika penulis melakukan pengamatan observasi di desa Pidoli Lombang dan mengikuti pengajian tersebut dalam pengajian parkahanggian ini memang benar bahwasannya rentetan pelaksanaan dan bacaan yang dibaca dalam pengajian parkahanggian ini sesuai dengan yang dijelaskan informan di atas, demikian pengajian parkahanggian pada malam Jum'at tersebut dilaksanakan.(Pidoli 2021b:Januari-1)

Sesuai dengan penjelasan di atas penulis mencoba menganalisa prosesi acara pelaksanaan pengajian. Menurut pengamatan penulis dalam pelaksanaan pengajian parkahanggian ini ada beberapa fase yang ada pada pelaksanaan pengajian parkahanggian ini. Pertama fase pembacaan ayat suci alQur'an, tahlil dan doa, kedua fase markobar (berbicara), yang ketiga fase marpio (memanggil nama untuk sumbangan iuran).

Markobar dalam bahasa Mandailing dialih bahasakan kepada bahasa Indonesia adalah berbicara, markobar dapat diartikan sebagai pembicaraan resmi yang dilaksanakan dalam acara-acara di Mandailing.(KHAIRANI 2014:2) Dalam acara pengajian parkahanggian selepas berdoa selanjutnya adalah markobar (berbicara), di dalam markobar (berbicara) ini pula akan diumumkan apabila ada hajat atau ingin mengadakan acara (misalnya pernikahan dll) akan diberitahukan pada saat markobar (berbicara) ini, atau apabila ada masalah dalam pengajian tersebut maka akan diberitahu pada saat markobar dan masalah itu akan dipecahkan dan dimusyawarahkan disaat markobar (berbicara) tersebut.(Madan Batubara 2021:Januari-16) 
Az̧bar Nasution, Rusydi AM, Widia Fithri, Nilai Tolong-menolong dalam Tradisi Pengajian Parkahanggian Marga di Desa Pidoli Lombang Kabupaten Mandailing Natal (Kajian Living al-Qur'an)

Kemudian setelah penulis melakukan observasi pada saat pelaksanaan pengajian menurut hemat penulis, marpio ini maksudnya adalah pemanggilan nama untuk iuran sedekah, nama tersebut akan dipanggil oleh salah seorang anggota, dan yang terpanggil namanya secara bergiliran akan memberikan sumbangan iurannya.(Pidoli 2021a:Januari-1) Dalam hal ini salah seorang informan bernama Sein masyarakat desa Pidoli Lombang menjelaskan hal yang sama terkait marpio ini beliau juga menjelaskan selesai pemanggilan nama, maka akan diumumkan pula giliran siapa untuk mengaji malam Jum'at yang akan datang dan begitu seterusnya. Menurut Sein sumbangan tersebut berlaku kepada anggota pengajian parkahanggian dan itu diberikan setiap malam Jum'at selepas selesai pengajian pada marpio tersebut sebanyak 2 ribu rupiah, uang sedekah ini akan difungsikan kepada anggota atau masyarakat yang membutuhkan nantinya baik itu dalam acara kemalangan atau pesta dan acara lain.(Sein Borotan 2021:Januari-15)

Ketiga, Bacaan Pengajian Parkahanggian, Berdasarkan hasil wawancara dengan Abdul Bais bacaan dalam tradisi pengajian parkahanggian ini dimulai dengan membaca ayat-ayat al-Qur'an dan juga shalawat. Terkait dengan ayat al-Qur'an tersebut meliputi surah al-Fatihah, al-Ikhlas, al-Falaq, an-Nas, alBaqarah setelah itu bacaan tahlil dan ditutup dengan doa.(Abdul Bais Nasution 2021:Maret-12)

Penulis coba mendalami dari argumen Abdul Bais kenapa ayat dan surah tersebut yang dibacakan dalam pengajian parkahanggian, beliau menjelaskan bahwa ayat dan surah tersebut adalah suatu yang sudah lumrah dibacakan memang mulai dari dahulu bacaan yang dibaca tetap ini sampai sekarang, surah dan ayat ini juga mempunyai manfaat yang besar, terlebih amalan kepada keluarga yang telah terdahulu.(Abdul Bais Nasution 2021:Maret-12) Temuan selanjutnya berasal dari Amrin Borotan SH beliau 
Az̧bar Nasution, Rusydi AM, Widia Fithri, Nilai Tolong-menolong dalam Tradisi Pengajian Parkahanggian Marga di Desa Pidoli Lombang Kabupaten Mandailing Natal (Kajian Living

menjelaskan bahwa dalam bacaan pengajin ini bukan hanya ayat-ayat alQur'an seperti al-Fatihah sebagai Ummul al-Qur'an dan ayat lain yang dibacakan, disini juga ada shalawat kepada nabi dengan menandakan bahwa bacaan pengajian ini adalah bacaan yang memiliki manfaat yang bagus bagi yang membacakan dan membacanya dalam posisi berjamaah.(Amrin Borotan SH 2021:Maret-12)

Unan seorang tokoh adat di desa Pidoli Lombang menjelaskan bahwa untuk pemandu atau pembawa bacaan pengajian tidak dipatokkan, baik itu yang tua ataupun yang muda, karena menurutnya semua sama, dan supaya sama-sama bisa dan sama-sama belajar, di pengajian parkahanggian ini dianjurkan kepada yang muda-muda tersebut untuk memandu supaya mereka pandai dan bisa, tidak mesti yang tua yang harus memandu.(Unan Rangkuti 2021:Januari-15).

Menurut hemat penulis ketika diselaraskan dengan teori living alQur'an yang bermakna menjadikan al-Qur'an itu hidup di tengah-tengah masyarakat,(Junaedi 2015:4) pengajian parkahanggian ini adalah suatu bentuk resepsi penghidupan al-Qur'an di tengah masyarakat dengan pembacaan ayat al-Qur'an yang rutin dilakukan pada malam Jum'at di desa Pidoli Lombang ini, dan juga mengamalkan ayat yang menganjurkan untuk saling tolongmenolong. Pengajian ini adalah salah satu langkang bahwa ayat-ayat al-Qur'an hidup dan dibacakan secara rutin dan bersamaan dan ayat al-Qur'an sebagai perintah, petunjuk atau stimulant untuk melakukan sesuatu.(Rafiq 2020:xxi) Tradisi unik ini juga merupakan kecintaan masyarakat terhadap ayat al-Qur'an juga sebagai amal ibadah bagi diri sendiri.

\section{Hikmah dan Nilai Tolong-menolong dalam Tradisi Pengajian Parkahanggian}


Az̧ar Nasution, Rusydi AM, Widia Fithri, Nilai Tolong-menolong dalam Tradisi Pengajian Parkahanggian Marga di Desa Pidoli Lombang Kabupaten Mandailing Natal (Kajian Living al-Qur'an)

Syukur menjelaskan dampak yang dirasakan adalah bermanfaat bagi keluarga dirumah yang mengadakan pengajian dan mendapatkan pahala bagi yang membacakan ayat-ayat al-Qur'an tersebut, dalam pengajian ini seperti membaca surah al-Fatihah, al-Ikhlas, an- Nas sampai kepada bershalawat dan doa. Ia menjelaskan fungsi dan manfaatnya ialah yang pertama kepada ahli bait, maksudnya adalah manfaat kepada keluarga yang dirumah tersebut, kemudian manfaat bagi yang mengaji tersebut karena dengan mengaji akan mendapatkan pahala, setelah itu manfaat dan fungsinya itu adalah kepada kaum muslimin dan muslimat untuk penerang dalam kuburnya apabila gelap, dilapangkan oleh Allah apabila sempit, dengan manfaat bacaan tersebut dijadikan Allah sebagai tanam-tanamannya di surga, tegasnya agar supayang keluarga yang sudah mendahului kita merasa lapang kuburnya, itulah manfaat yang dirasakan.(Syukur 2021:Januari-16).

Makna yang mendalam dari pengajian parkahanggian ini juga diungkap oleh Bayo salah seorang masyarakat desa Pidoli Lombang, beliau mengatakan bahwa pengajain parkahanggian ini bukan hanya sekedar pengajian akan tetapi keluarga tempat saling membantu antara satu dengan yang lain, dengan rasa kekeluargaan apabila terjadi sesuatu, banyak hikmah yang diperoleh dari pengajian parkahanggian ini, semisal yang utama bahwa kita masih mempunyai saudara dan keluarga disini dengan adanya pengajian parkahanggian ini, masih ada tempat mengadu, masih ada yang membantu kita sekiranya apapun yang terjadi di kampung ini tuturnya.(Bayo 2021:Januari-17)

Selain manfaat yang dirasakan bagi yang masih hidup, di pengajian parkahanggian ini juga berdampak manfaat bagi keluarga yang telah terdahulu, terlihat dari niat di awal bacaan bahwa tujuannya agar supaya ayatayat yang dibaca mengalir pahalanya kepada keluarga yang telah terdahulu, 
Az̧ar Nasution, Rusydi AM, Widia Fithri, Nilai Tolong-menolong dalam Tradisi Pengajian Parkahanggian Marga di Desa Pidoli Lombang Kabupaten Mandailing Natal (Kajian Living al-Qur'an)

dalam hal ini dihadiahkanlah ayat al-Qur'an yang dibacakan tersebut sampai kepada keluarga dan kaum muslimin yang telah terdahulu, segala surah-surah yang dibacakan pahalanya akan sampai kepada keluarga kita yang telah meninggal.(Abdul Bais Nasution 2021:Januari-16)

Syukur juga menuturkan bahwa ada hadis Nabi yang menjelaskan tentang pahala yang tidak putus, dan langsung mengalir kepada kelarga yang telah terdahulu, hadis tersebut adalah patokan bahwa amal yang dilakukan seperti mengaji tersebut akan mengalir pahalanya, hadisnya sadakatun jariah

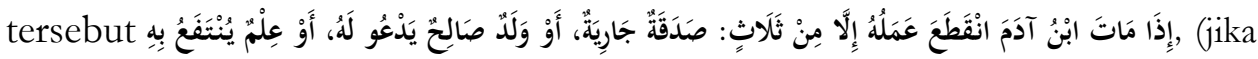
seseorang meninggal dunia, maka terputuslah amalannya kecuali tiga perkara: sedekah jariah, anak yang soleh, ilmu yang dimanfaatkan), yang pertama disebutkan sedekah jariah, yang selanjutnya adalah anak yang soleh atau doa anak yang soleh, contonya dengan mengikuti pengajian parkahanggian tersebut, secara otomatis pahala yang dibacakan tersebut akan mengalir kepada orang tua, tanpa ada syarat maupun penghalang akan mengalir pahalannya secara khusus dan otomatis kepada orang tua, dan mudahmudahan kuburnya lapang-lapang, itulah salah satu fungsinya, yang kedua manfaatnya adalah kepada oaring yang masih hidup, kita sebenarnya tidak ada beda dengan orang yang telah meninggal dan yang masih hidup, bedannya hanyalah jasad, akan tetapi masalah ruhnya masih sama, namun jasadnya yang meninggal, dan dihadiahkanlah bacaan tersebut kepada ruhnya, sebenarnya antara orang yang meninggal dan hidup sama-sama mendapat pahala, itulah fungsinya tuturnya.(Syukur 2021:Januari-16).

Masyarakat Pidoli Lombang bukan hanya membacakan ayat-ayat alQur'an yang diistilahkan sebagai pengaiian parkahanggian yang menyatukan antara budaya dan agama, budaya maksudnya parkahanggian itu sendiri dan keagamaannya adalah resepsi pembacaan ayat-ayat al-Qur'an tersebut, yang 
Az̧bar Nasution, Rusydi AM, Widia Fithri, Nilai Tolong-menolong dalam Tradisi Pengajian Parkahanggian Marga di Desa Pidoli Lombang Kabupaten Mandailing Natal (Kajian Living al-Qur'an)

akrab diistilahkan masyarakat sebagai pengajian parkahanggian. Syukur menjelaskan dalam pengajian ini terungkap makna yang dalam, bukan hanya pengajian akan tetapi bagi masyarakat Pidoli Lombang pengajian ini menjadi wadah untuk saling tolong-menolong dan al-Qur'an juga telah menjelaskan betapa pentingnya sikap saling menolong ini.(Syukur 2021:Januari-16) Dapat disimpulkan bahwa al-Qur'an bukan hanya diterima sebagai kitab suci yang dibaca, akan tetapi lebih kepada pengamalan makna yang terkandung di dalam ayat al-Qur'an tersebut diamalkan oleh masyarakat sesuai dengan penjelasan teori di atas bahwa teks ayat al-Qur'an diterima serta diamalkan dan difungsikan secara performatif yang melahirkan berbagai perilaku seharihari serta pemahaman terhadap ayat tersebut dipraktekkan di masyarakat. (Rafiq 2014:155)

Kemudian Unan Rangkuti menjelaskan bahwa bentuk tolongmenolong yang ada dalam pengajian parkahanggian ini adalah dalam acara adat pernikahan dan acara kemalangan semua kahanggi (saudara semarga) akan membantu saudaranya yang mengadakan acara tersebut.(Unan Rangkuti 2021:Januari-15) Oji juga menyebutkan bahwa bukan hanya tenaga yang disumbangkan apabila ada pelaksanaan hajatan pesta atau kemalangan, namun bantuan dari bentuk uang juga diberikan untuk meringankan beban saudara.(Oji Abdullah 2021:Januari-17) Sesuai dengan observasi yang penulis lakukan dan penjelasan informan di atas dari analisa penulis bentuk bantuan yang dilakukan parkahanggian antar semarga ini adalah ada yang berbentuk materi, ada yang berbentuk tenaga atau jasa, dan ada juga yang berbentuk pikiran yang disumbangkan kepada yang mengadakan acara baik pernikahan atau kemalangan. Tampak dari praktek di atas nilai-nilai yang berkembang di dalam tolong-menolong pada pengajian parkahanggian menjadi nilai penting, maka dari sinilah terlihat nilai tolong-menolong tersebut yang mengandung 
Az̧ar Nasution, Rusydi AM, Widia Fithri, Nilai Tolong-menolong dalam Tradisi Pengajian Parkahanggian Marga di Desa Pidoli Lombang Kabupaten Mandailing Natal (Kajian Living

makna nilai kesatuan, persatuan, persaudaraan, dalam tolong-menolong pada pengajian parkahanggian ini juga mengandung nilai kebersamaan dan kerukunan antar masyarakat.

\section{PENUTUP}

Berdasarkan kajian di atas, dapat ditarik kesimpulan bahwa hasil temuan menjelaskan pengajian parkahanggian ini adalah suatu kegiatan keagamaan yang membacakan ayat-ayat al-Qur'an di dalamnya, bukan hanya itu pengajian ini merupakan wadah untuk saling bertolong-tolongan antar yang bersaudara semarga, dalam tradisi ini terdapat nilai-niali al-Qur'an yang difahami dan diamalkan. Tradisi ini telah lama dilakukan, dugaan yang kuat berasal dari syaikh Ma'sum di daerah tersebut. Acara pengajian parkahanggian ada 3 fase, fase pertama membacakan ayat-ayat al-Qur'an, fase kedua acara markobar (berbicara), fase ketiga marpio (pemanggilan nama).

Motivasi masyarakat dalam melakukan tradisi ini adalah untuk beribadah dengan membaca ayat al-Qur'an, saling tolong-menolong dan menyambung tali silaturrahim diyakini membawa dampak yang baik bagi masyarakat agar dapat membantu dan meringankan beban saudara yang membutuhkan, melestarikan tradisi, selain itu menjadi ibadah bagi yang membaca serta hadiah berupa pahala bagi keluarga yang telah terdahulu, dan hikmah yang dirasakan bukan hanya kepada orang masih hidup orang yang sudah meninggal pun mendapatkan kiriman pahala. Nilai tolong-menolong tersebut dalam suasana suka maupun duka yang mengandung makna nilai kesatuan, persatuan, persaudaraan.

\section{DAFTAR REFERENSI}

Ali, Muhamad. (2015). "Kajian Naskah dan Kajian Living Qur'an dan Living Hadith." Journal of Qur'an And Hadith Studies. 4(2) 
Az̧ar Nasution, Rusydi AM, Widia Fithri, Nilai Tolong-menolong dalam Tradisi Pengajian Parkahanggian Marga di Desa Pidoli Lombang Kabupaten Mandailing Natal (Kajian Living al-Qur'an)

Asrin, Ahmad. (2020). "Revitalisasi Pendidikan Keagamaan Islam di Mandailing Natal." Jurnal Ilmiah Al-Hadis. 5(1).

Azwar, Saifuddin. (2016). Metode Penelitian. Yogyakarta: Pustaka Belajar.

Effendi, Heri. (2018). "Kontekstualisasi Fungsi Bagas Godang dan Sopo Godang Sebagai Sumber Pembelajaran Sejarah Lokal.” Diakronika. 18 (2).

Fitri, Wanseha. (2019). "Nilai Ta'awun dalam Tradisi Begawi (Kajian Living Qur'an)."

Istianah, Nana. (2020). "Pemaknaan Tradisi Pembacaan al-Qur'an di PT Karya Toha Putra Semarang (Studi Living Qur'an).” Retrieved July 8, 2021 (http://e-repository.perpus.iainsalatiga.ac.id/8604/).

Junaedi, Didi. (2015). "Living Qur'an: Sebuah Pendekatan Baru dalam Kajian al-Qur'an (Studi Kasus Di Pondok Pesantren As-Siroj Al-Hasan Desa Kalimukti Kec. Pabedilan Kab. Cirebon)." Journal of Qur'an and Hadith Studies. 4(2)

Khairani, Fauziah. (2014). "Kearifan Mandailing dalam Tradisi Markobar." Jurnal Bahas Unimed. 25 (3)

Kristi, Elizabeth. (2021). "Implementasi Tolong-Menolong Di Organisasi Aksi Cepat Tanggap Riau Dalam Perspektif Al-Qur'ān (Studi Living Quran)."

M. Mansyur, ed. (2007). Metodologi penelitian living Qur'an dan Hadis / M. Mansyur. Yogyakarta: TH-Press.

Makhdlori, Muhammad. (2019). Mukjizat-Mukjizat Membaca al-Qur'an. Jogjakarta: Diva Pers.

Nashir, Haedar. (2019). Ta'awun Untuk Negeri. Jakarta: Majlis Pustaka.

Nuraini, Nuraini, and Wardahtul Jannah. (2020). “Tradisi Mengaji Al-Qur'an Di Kuburan Dalam Masyarakat Indonesia." Tafse: Journal of Qur'anic Studies. 5 (2).

Putra, Adi Mandala, and Ambo Upe Bahtiar. (2018). "Eksistensi Kebudayaan Tolong Menolong (Kaseise) Sebagai Bentuk Solidaritas Sosial Pada Masyarakat Muna (Studi Di Desa Mataindaha Kecamatan Pasikolaga)." Jurnal Neo Societal. 3 (2)

Rafiq, Ahmad. (2014). The Reception of the Qur'an in Indonesia: A Case Study of the Place of the Qur'an in a Non-Arabic Speaking Community. Temple University. 
Az̧bar Nasution, Rusydi AM, Widia Fithri, Nilai Tolong-menolong dalam Tradisi Pengajian

Parkahanggian Marga di Desa Pidoli Lombang Kabupaten Mandailing Natal (Kajian Living al-Qur'an)

Rafiq, Ahmad. (2020). Living Qur'an: Teks, Praktik, dan Idealitas dalam Performasi al-Qur'an. Yogyakarta: Lembaga Ladang Kata.

Sangadji, Etta Mamang, and Sopiah. (2010). Metodologi Penelitian. Yogyakarta: CV. Andi Offset.

Simamora, Tia Subu. (2021). "Tradisi Pembacaan Yasin 41 Studi Living Qur'an.” Jurnal El Thawalib. 2 (2)

Sudarmoko, Imam. (2016). “The Living Qur'an: Studi Kasus Tradisi Sema’an Al-Qur'an Sabtu Legi Di Masyarakat Sooko Ponorogo."

Sugesti, Delvia. (2019). "Mengulas Tolong Menolong Dalam Perspektif Islam." Pelita Bangsa Pelestari Pancasila. 14 (2)

Suriani, Erma. (2018). “Eksistensi Qur'anic Centre Dan Ekspektasi Sebagai Lokomotif Living Qur'an Di UIN Mataram.” Jurnal Penelitian Keislaman. 14 (1)

Zuhri, and Sahiron Syamsuddin. (2012). Islam, Tradisi, Dan Peradaban. Sewon, Bantul, Yogyakarta: Diterbitkan oleh Bina Mulia Press bekerjasama dengan Penerbit Suka-Press.

\section{Wawancara}

Samsuddin, wawancara langsung, Alim Ulama di desa Pidoli Lombang , 15 Januari/8 Maret 2021.

Unan, wawancara langsung, (Hatobangon) Tokoh adat desa Pidoli Lombang , 15 Januari 2021.

Sein Borotan, wawancara langsung, masyarakat desa Pidoli Lombang, 15 Januari 2021.

Amrin Borotan SH, wawancara langsung, Tokoh Masyarakat Desa Pidoli, 12 Maret 2021.

Fahri Lubis, wawancara langsung, Pemangku adat desa Pidoli Lombang, 16 Januari/ 8 Maret 2021.

Syukur, wawancara langsung, Tokoh Agama di desa Pidoli Lombang, 16 Januari 2021.

Madan Batubara, wawancara Langsung, masyarakat desa Pidoli Lombang, 16 Januari 2021. 
Az̧har Nasution, Rusydi AM, Widia Fithri, Nilai Tolong-menolong dalam Tradisi Pengajian Parkahanggian Marga di Desa Pidoli Lombang Kabupaten Mandailing Natal (Kajian Living al-Qur'an)

Abdul Bais Nasution, wawancara langsung, guru mengaji di desa Pidoli Lombang, 16 Januari/12 Maret 2021.

H. Aslen Borotan, wawancara langsung, kepala desa/ tokoh agama Pidoli Lombaang, 17 Januari 2021.

Muda Mustari, wawancara langsung, guru mengaji di desa Pidoli Lombang, 17 Januari 2021.

Oji Abdullah, wawancara langsung, tokoh agama desa Pidoli Lombang, 17 Januari 2021.

Bayo, wawancara langsung, warga desa Pidoli Lombang, 17 Januari 2021. 